\title{
Integrated Methods of Control of Body Weight, Appetitis and Food Behavior Using Short-Term Inhalations of High-Concentrated Oxygen with Adding of Grapefruit Oil
}

\author{
Oksana Khukhlina, $\mathrm{PhD}, \mathrm{MD}^{1 *}$, Eugene Shorikov, $\mathrm{PhD}, \mathrm{MD}^{2}$ \\ ${ }^{\mathrm{T}}$ Professor, Doctor of Medical Sciences, Department of Internal Medicine, Clinical Pharmacology and Occupational \\ Diseases, Higher State Educational Institution of Ukraine «Bukovinian State Medical University», Fastivska str. \\ ${ }^{2}$ Professor, Doctor of Medical Sciences, Chernivtsi, Ukraine, 58000
}

\section{*Corresponding Author}

Oksana Khukhlina, $\mathrm{PhD}$, MD

\section{Article History}

Received: 31.03 .2020

Accepted: 08.04.2020

Published: 14.04.2020

\begin{abstract}
The article presents the results of using an integrated method of controlling body weight, appetite and eating behavior while using short-term inhalations of highly concentrated oxygen with the addition of grapefruit oil. Material and methods: The work included 33 people (mean age 39.5 \pm 6.1 years) with overweight. Anthropometric measurements, assessment of eating behavior disorders, questionnaires carried out. The subjects were divided into two groups: group 1 (18 people), where a low-calorie diet, training sessions, and high-concentration oxygen inhalations were prescribed (Tesla's Secret by Eco Medical Europe Ltd Oxygen Breathing Mixture, Natural); group 2 (15 people), whose in addition to physical activity and diet has received inhalation of highly concentrated oxygen by adding grapefruit aroma oil (Oxygen Breathing Mixture Grapefruit). The results of the study: It was found that the most common form of eating behavior disorder is emotiogenic $(60.6 \%)$, with an average score of $3.87 \pm 0.65$. In group 2 , in the dynamics of observation, the score for emotiogenic and external eating behavior statetement decreased, and the restrictive type of eating behavior became dominant. Inhalation of highly concentrated oxygen with the addition of grapefruit oil helped to reduce hunger on the visual analogue scale by $72.2 \%(\mathrm{p}<0.05)$, increased the feeling of fullness by $14.1 \%(\mathrm{p}<0.05)$, the parameters "Thoughts on food" and "Desired amount of food" decreased by $97.6 \%$ and $21.9 \%(p<0.05)$. Analysis of the stage-by-stage control data revealed a positive dynamics of the main indicators - a decrease in body weight, as well as a body mass index. In group 2, where inhalation of highly concentrated oxygen with the addition of grapefruit oil was used, a more significant changes $(12.6 \%, \mathrm{p}<0.05)$ were achieved against group 1 , where the decrease in average body weight was $4.3 \%$. In terms of body mass index in group 1, the decrease in BMI was 7.3\%, in group $2-19.7 \%$. It was proved that a more reliable decrease in BMI, WC, TC and WC/TC ratio was detected in patients of the group 2 ( $\mathrm{p}<0.05$ ), who received a comprehensive program with inhalation of highly concentrated oxygen with grapefruit oil. Both groups showed a decrease in WC, TC and WC/TC ratios, but signs of abdominal distribution of adipose tissue persisted.
\end{abstract}

Keywords: Body weight, appetite control, eating behavior, inhalation of highly concentrated oxygen, grapefruit oil.

\section{INTRODUCTION}

The influence of various external factors physical, chemical and biological nature, as well as the internal processes of the human body lead to the increased accumulation of various free radicals. The oxidative stress develops with the accumulation of active forms of oxygen or nitrogen, which leads to disruption of the normal functioning of the body systems and enhanced oxidative damage to biomolecules and can be an important cuase of various diseases or complications $[2,3]$.

Endogenous sources of free radicals are associated with life processes of the cell and the various enzymatic and protective reactions in the human body. Oxygen is essential for aerobic living cells of the body, but at the same time causes the formation of free radicals and, as a consequence, the development of oxidative stress in the body [8].

Copyright @ 2020: This is an open-access article distributed under the terms of the Creative Commons Attribution license which permits unrestricted use, distribution, and reproduction in any medium for non commercial use (NonCommercial, or CC-BY-NC) provided the original author and source are credited. 
Obesity belongs to the major public health problems [5]. Over the last 50 years obesity has become the nature of the pandemic, and each year an increasing number of patients still suffer from obesity. Obesity should be viewed not just as a cosmetic defect, but serious disease that may lead to the development of the most severe fatal complications (acute MI, a sleep apnea syndrome, colorectal cancers, breast cancer). It is known that obesity is one of the major risk factor for the development and progression of chronic heart failure (CHF), hypertension, type 2 diabetes [6, 15]. In the Framingham study, it was shown that the risk of CHF depends on BMI in men and women [11].

Recent studies also indicate significant mental disorders (diseases) depending on obesity, which have a significant effect on the formation of a pathological food stereotype and various forms of eating disorders (ED) [17]. According to Voznesenskaya T. G. et al., in addition to a genetically determined predisposition, the leading role in the pathogenesis of visceral and abdominal obesity is set by dysregulation of eating behavior at the level of the hypothalamic-pituitary system, where the main clusters of food addiction are formed. In turn, a disturbance of the food stereotype is one of the dominant factors in the development of metabolic syndrome in adults [16].

Grapefruit, due to the presence of biologically active substances - vitamins, minerals, furacumarins, organic acids, flavanoids, sugars, have antioxidant, hypolipidemic, hepatoprotective, antitumor properties. Analysis of the antioxidant activity of grapefruit showed that the value of the antioxidant activity of its extract is $9.74 \mathrm{mmol} / 1 \mathrm{x}$ equiv. Fresh grapefruit fruits contain organic acids, glucose $1.77 \%$, fructose $1.37 \%$, sucrose up to $3.1 \%$, vitamin C. Sucrose is the dominant carbohydrate of grapefruit and the ratio of fructose to glucose is 1:1 [12]. Furacumarins bergamottin, bergapten, bergaptol and 6', 7'-dihydroxybergamotine [14] were determined. Grapefruit juice contains flavanoids naringin, naringenin, narirutin, quercetin, kempferol, hesperidin, neohesperidin, didumin, ponzirin, and sesquiterpenes [7]. Flavonoin glycoside naringin has been determined in the peel and pulp of fruits. The color of the grapefruit cellulose is mainly determined by the ratios of zeaxanthin, $\beta$-cryptoxanthin and lycopene. Grapefruit fruits have a large amount of salts of $\mathrm{K}^{+}, \mathrm{Na}^{+}, \mathrm{Mg}^{2+}$. Grapefruit juice has apparent antioxidant and antigenotoxic properties [12].

Dry extract of grapefruit is effective option for reducing abdominal fat, waist and thigh circumference, and body weight and for the improving of inflammatory, glycemic, and oxidative status in healthy people with overweight. The administration of grapefruit juice improves insulin resistance, reduces damage caused by free radicals, protects the lipids of the liver, and stimulates the hepatic activity of the glutathione S-transferase, glutathione peroxidase and catalase enzymes [1].

At present, the food addiction is considered from the perspective of effects of stress and disturbance of the regulatory role of neuropeptides. The deficiency of endorphins (produced in the pituitary gland, adrenal glands, ovaries, testes, pancreas) leads to depression, prolongation of stress, exacerbation of chronic diseases, to the development of obesity, diabetes mellitus type 2, implements the genetically determined pathological addictions (drugs, alcohol, "food intemperance"). People with hyperphagia need a food, not as a source of energy but as a necessacity of endorphins hyperproduction of eating for pleasure, that has been given the WHO the reason to equate a food addiction with the same drug one. One of the leading causes in the formation of eating disorders is a hereditary dysfunction of the cerebral systems regulating food intake, in which the largest value belongs to a serotonin deficiency. Published nowadays, the research findings help to construct in patient with a high body mass index (BMI) the following chronology of events: the ingestion of carbohydrate with emotional discomfort (experiencing up to $95 \%$ of adults with obesity) $>$ the resulting blood glucose level > hyperinsulinemia > increased permeability of the blood-brain barrier to tryptophan while increasing its levels in the central nervous system $>$ increased synthesis of serotonin $[9,13]$.

In clinical practice, there are 3 main types of ED disturbance: external, emotional, and restrictive. External ED is manifested by an increased reaction of the patient not to homeostatic, internal stimuli to eat (glycemia, lipidemia, mechanical distension of the stomach, etc.), but to external ones (covered table, type of food) [18].

Emotiogenic ED (a synonym for hyperphagic reaction to stress) is most common among obese adults and occurs in $60 \%$ of these patients [4]. This form is characterized by emotional overeating, when the stimulus for eating is not hunger, but emotional discomfort.

Restrictive eating behavior includes nutritional self-restraint and unsystematic strict diets, accompanied by decompensation in the mental and vegetative spheres. Periods of restrictive eating behavior give way to periods of overeating with recurring intense weight gain [4].

Therefore, the importance of correction of eating behavior in obese patients is the basis of therapy. The struggle against obesity is an important component in the prevention of serious "complications" and deserves close attention from the physician $[16,17]$. 
The purpose of the work is to evaluate the effect of inhalation of highly concentrated oxygen with the addition of grapefruit oil on the level of appetite, type of eating desorder, and body weight and weight-growth indices in overweight people.

\section{Materials ANd Methods}

A prospective 60 -day study was conducted, in which 33 people aged $37-45$ years participated (25 women and 8 men, with mean age $39.5 \pm 6.1$ years). All the subjects were conditionally healthy, were dissatisfied with their body weight and expressed a desire to reduce it.

Body weight was considered excessive at a BMI of more than $25 \mathrm{~kg} / \mathrm{m} 2$, obesity was determined with a BMI of more than $30 \mathrm{~kg} / \mathrm{m} 2$. The criterion for inclusion in the study was the presence of abdominal obesity (the ratio of the waist circumference to the circumference of the hips WC/TC> 0.94 for men and more than 0.8 for women), body mass index (BMI) is more than $25 \mathrm{~kg} / \mathrm{m} 2$ ).

Based on the results of the body mass index, 15 patients $(45.5 \%)$ were overweight, 10 people have obesity I $(30.3 \%)$ degree, 8 people have obesity of the II degree $(24.2 \%)$. The study was carried out taking into account the requirements of the Helsinki Declaration of Human Rights; all participants in the study gave written informed consent.

All subjects underwent anthropometric measurements (body weight $(\mathrm{kg})$, height $(\mathrm{cm})$, waist $(\mathrm{cm})$ and hips $(\mathrm{cm})$, shoulder index (rel. (points), questionnaire.

Evaluation of anthropometric indicators was carried out according to a standard unified methods: height was measured using a bar anthropometer with an accuracy of $0.5 \mathrm{~cm}$, body weight on electronic medical scales VEM-150"Massa-K" with an accuracy of $60 \mathrm{~g}$. Waist circumference (WC) was measured by flexible centimeter tape in the middle of the distance between the apex of the iliac crest and the lower lateral edge of the ribs. The thigh circumference (TC) was recorded in a standing position at the level of the pubic symphysis in front and the greater trochanter of the femur on the side.

Body mass index (BMI) was calculated as the ratio of body weight, expressed in kilograms, to the square of growth, expressed in meters. The adipose tissue distribution index was considered equal to the ratio of the waist circumference to the hips circumference (WC / TC).

The presence of eating disorders and assessment of their types was carried out using a modified DEBQ questionnaire developed by T. Van Strein et al. and containing 10 questions. Regulatory data of questionnaires (in points): external ED - 2.68; emotiogenic ED - 2.03; restrictive ED - 2.43.

The weight correction program has begun with individual enhanced motivation to reduce body weight, as well as the formation of realistic expectations and achievable goals. In order to correct overweight, recommendations were made on lifestyle changes. The basis was a balanced rational diet: hypocaloric (daily calorie deficit should be 500-600 kcal), with a restriction of fats up to $30 \%$ of the daily diet and table salt to 5 grams per day, refusal from alcohol consumption, as well as an increase in the proportion of foods in the diet, rich in complex carbohydrates, plant fibers and sufficient animal protein. The daily energy consumption was calculated individually for all subjects. The average caloric content of the diet was 1600-1800 kcal / day. In addition, everyone was offered a program of short-term training sessions - physical exercises were carried out taking into account heart rate corresponding to the thresholds of aerobic and anaerobic metabolism. The duration of one lesson was 55 minutes.

The subjects were divided into two groups depending on the method of therapy with the goal of weight correction: group 1 (14 people) who followed a low-calorie diet (1600-1800 kcal/day), a program of short-term training sessions with dosed walking, and those who used inhaled highly concentrated oxygen (Tesla's Secret by Eco Medical Europe Ltd Oxygen Breathing Mixture, Natural); group 2 (18 people) who followed a low-calorie diet, a program of short-term training sessions with dosed walking and passed a course of short-term inhalation of highly concentrated oxygen by adding grapefruit (Oxygen Breathing Mixture Grapefruit). Inhalations were carried out three times a day before the main meal use. Meal was taken after 10-15 minutes after inhalation and an appetite self-test. The total period of controlled observation was 6 months.

For statistical analysis of the obtained results, we used Statistica for Windows Version 10.0 (Stat Soft inc., USA). Parameters are presented in $\mathrm{M} \pm \mathrm{m}$, where $\mathrm{M}$ is the mean and $\mathrm{m}$ - is standard deviation. At the $\mathrm{p}<0.05$, differences were set as a significant. 


\section{RESEARCH RESUlTS AND DiscuSSION}

The data obtained showed that the most common form of eating disorder was emotiogenic (20 people $60.6 \%$ ), the average score was $3.87 \pm 0.65$ out of 5 . This type of behavior was also accompanied by the main symptoms of the clinical "triad" syndrome: night food, morning anorexia and evening bulimia. 8 people $(24.2 \%)$ had an external type of eating disorder with an average score of 3.18 \pm 0.18 . A restrictive type of eating disorder was found in 5 subjects $(15.2 \%)$. More often than not, these were chaotic and unsystematic food restrictions that did not lead to weight loss, but, on the contrary, were combined with an increase in body weight, since periods of severe but unsystematic food restrictions are usually followed by periods of overeating.

It must be emphasized that $75.8 \%$ of the respondents (25 people), prior to the survey, did not always objectively assess the presence of eating disorders and did not consider the fact of hyperphagia to be objective.

Appetite control was carried out on visual analogue scale (VAS) self-esteem, Table. 1.

Table-1: The dynamics of the VAS score in self-appetite in the examined patients with overweight and obesity

\begin{tabular}{|c|c|c|c|c|}
\hline \multirow{2}{*}{ Parameters } & \multicolumn{2}{|c|}{ Group 1 } & \multicolumn{2}{c|}{ Group 2 } \\
\cline { 2 - 5 } & Before inhalations & $\begin{array}{c}\text { After } \\
\text { Inhalations } \\
(\mathbf{1 0} \text { minutes })\end{array}$ & Before inhalations & $\begin{array}{c}\text { After } \\
\text { Inhalations } \\
(\mathbf{1 0} \text { minutes })\end{array}$ \\
\hline Hunger, $\mathbf{m m}$ & $35,8 \pm 3,45$ & $40,1 \pm 5,12^{*}$ & $36,5 \pm 3,18$ & $21,2 \pm 5,12^{*}, * *$ \\
\hline Satiation, $\mathbf{m m}$ & $55,6 \pm 4,23$ & $56,4 \pm 4,67$ & $57,3 \pm 3,98$ & $65,4 \pm 4,15 *, * *$ \\
\hline Thoughts on food, $\mathbf{m m}$ & $29,2 \pm 2,95$ & $31,5 \pm 3,43$ & $33,4 \pm 3,67$ & $16,9 \pm 3,12^{*}, * *$ \\
\hline Desired amount of food, $\mathbf{m m}$ & $28,4 \pm 3,56$ & $31,2 \pm 3,78$ & $29,5 \pm 4,19$ & $24,2 \pm 4,62^{*}, * *$ \\
\hline
\end{tabular}

Note: *significance of differences in the dynamics of observation $(\mathrm{p}<0.05)$

**reliability of the difference in indicators between groups 1 and $2(\mathrm{p}<0.05)$

It was noted that inhalation of highly concentrated oxygen with the addition of grapefruit oil contributed to a decrease in hunger sensation by VAS by $72.2 \%$ (from $36.5 \pm 3.18$ to $21.2 \pm 5.12$ points, $\mathrm{p}<0.05$ ), increased satiation by $14.1 \%$ (from $57.3 \pm 3.98$ to $65.4 \pm 4.15$ points, $p<0.05$ ), the "Thoughts on food" and "Desired amount of food" parameters decreased by $97.6 \%$ (from $33.4 \pm 3.67$ to $16.9 \pm 3.12$ points, $\mathrm{p}<0.05$ ) and $21.9 \%$ (from $29.5 \pm 4.19$ to $24.2 \pm 4.62$ points, $\mathrm{p}<0.05)$. At the same time, it should be noted that similar indicators in group 1 had slightly different trends - an increase in hunger (by 12.0\%), "Thoughts about food" (by 7.9\%), and also the "Desired amount of food" (by 9.9\%).

The lack of the correct food stereotype additionally characterizes the peculiar psycho-emotional appearance of people with excessive fat deposition and gives a likely explanation for the low compliance in the treatment of obesity. As a result, the correction of eating behavior with the rejection of the wrong eating stereotype is as complex as the treatment of other types of addictions.

The analysis of the stage-by-stage control data revealed a positive dynamics of the main indexes. After 3 months of a comprehensive approach to weight loss, body weight and body mass index of both groups decreased.

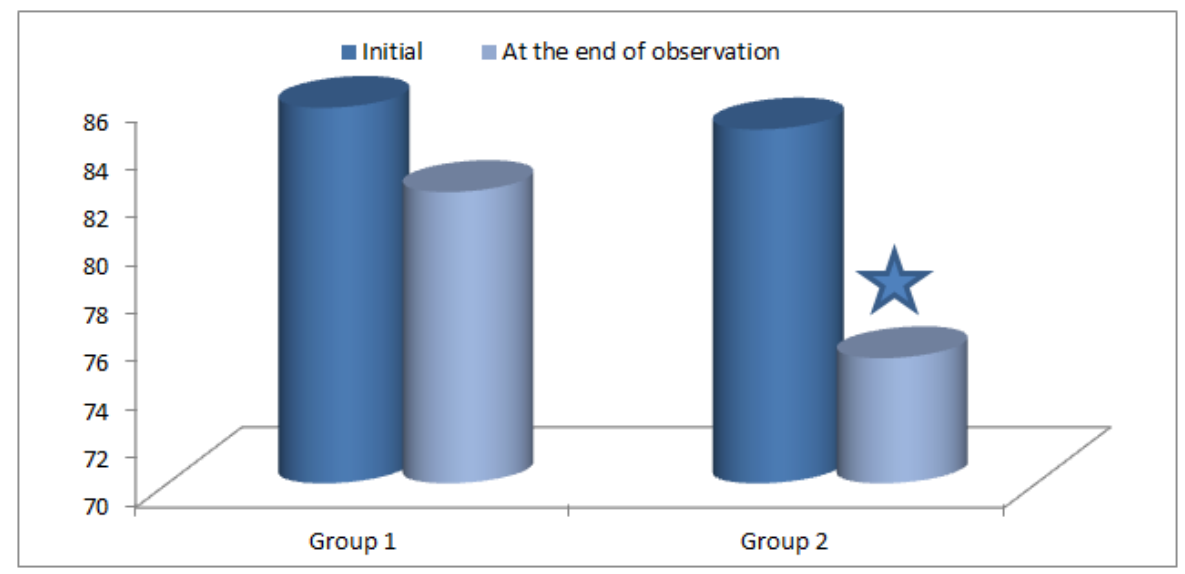

Fig-1: Dynamic of body mass changes in the observational groups

Note: The reliable differences in dynamic of observation $(\mathrm{p}<0,05)$. 
At the same time, it should be noted that in group 2, where inhalation of highly concentrated oxygen with the addition of grapefruit oil was used, a more significant $(\mathrm{p}<0.05)$ result in a decrease in body weight by $12.6 \%$ was achieved (from $84.7 \pm 6.76$ to $75.2 \pm 5.45 \mathrm{~kg}$ ) versus group 1, where the decrease in average body weight was only $4.3 \%$ (from $85.6 \pm 4.78$ to $82.1 \pm 5.11 \mathrm{~kg}$ ), Figure 1 .

A similar pattern of changes was revealed in the analyses of body mass index. The average decrease in BMI in group 1 was $7.3 \%$, but in group $2-19.7 \%$. There was not any person who would not reduce body weight. The median BMI was initially $32.6 \pm 2.95 \mathrm{~kg} / \mathrm{m} 2$ in group $1,32.8 \pm 3.11 \mathrm{~kg} / \mathrm{m} 2$ in group 2 . The dynamics showed a decrease in BMI to $30.4 \pm 2.87 \mathrm{~kg} / \mathrm{m} 2$ in group 1 and up to $27.4 \pm 1.95 \mathrm{~kg} / \mathrm{m} 2$ in group 2 .

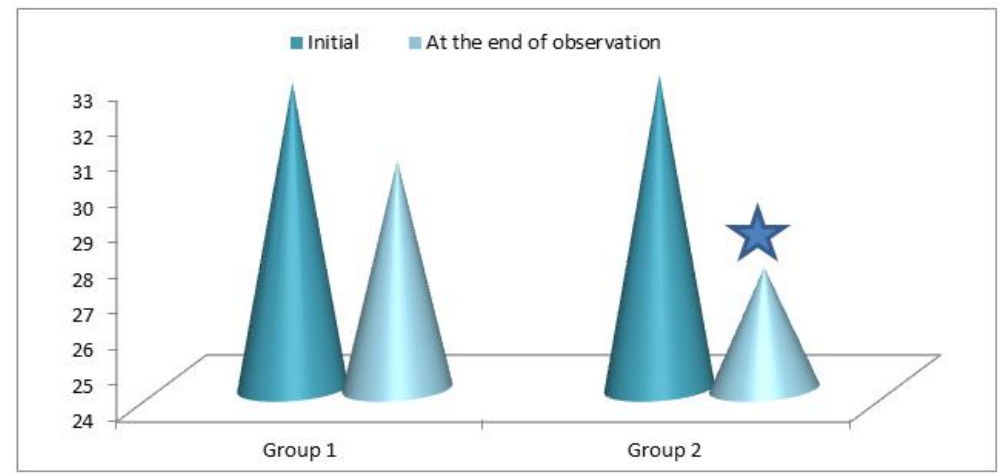

Fig-2: Dynamic of changes of body mass index in the observational groups

Note: The reliable differences in dynamic of observation $(\mathrm{p}<0,05)$.

A decrease in WC and TC was also noted (Figs. 3a and 3b), and the ratio of WC/TC (Fig. 4) also has changed, but signs of abdominal distribution of adipose tissue still remained.

In particular, the dynamics of WC was $6.82 \%$, the decrease in TC was $6.0 \%$ in group 1 (p>0.05), $17.2 \%$ and $9.6 \%$ in group $2(\mathrm{p}<0.05)$.

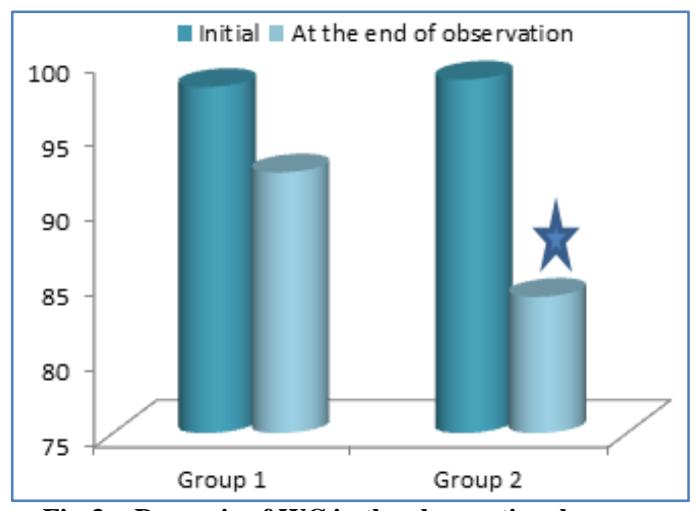

Fig-3a: Dynamic of WC in the observational groups

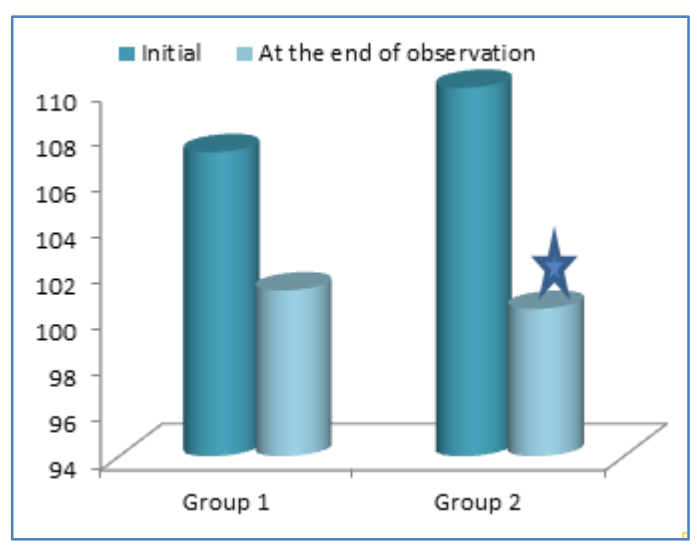

Fig-3b: Dynamic of TC in the observational groups

$\star$ Note: The reliable differences in dynamic of observation $(\mathrm{p}<0,05)$. 
2, Fig. 4.

Positive dynamics of the WC / TC ratio was also observed in both groups $-5.9 \%$ in group 1 and $8.1 \%$ in group

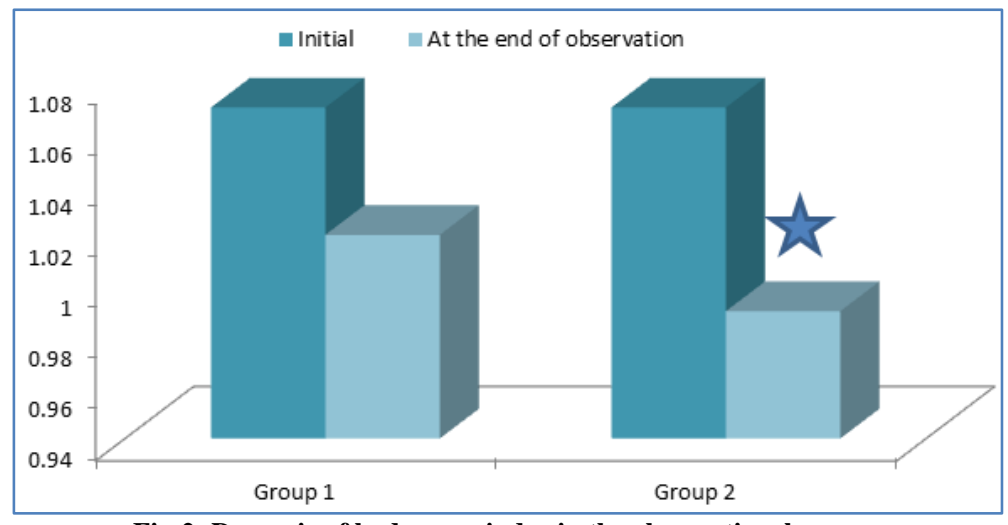

Fig-2: Dynamic of body mass index in the observational groups

$\star$ Note: The reliable differences in dynamic of observation $(\mathrm{p}<0,05)$.

The data obtained indicate that a more relible decrease in BMI, WC, TC and the ratio of WC/TC was detected in 2-nd group of patients, who received a comprehensive program with inhalation of highly concentrated oxygen with grapefruit oil.

At the same time, in the study, both groups showed a significant decrease in WC/TC after a comprehensive weight loss program.

In a comparative analysis of the personality characteristics of the subjects of the two subgroups, dispositions of eating behavior, the structure of self-esteem, and the level of self-esteem according to the beauty parameter turned out to be significant.

As can be seen from the table. 2, indexes of changes in eating behavior are overestimated in both groups of subjects compared with the standards typical for people with normal body weight. This indicates a disturbance in the eating behavior of the subjects, which, apparently, is one of the factors determining excess body weight.

Table-2: Dynamics of indicators of severity of dispositions of eating behavior in the observed groups

\begin{tabular}{|c|c|c|c|c|c|}
\hline \multirow{2}{*}{ Parameters } & \multicolumn{2}{|c|}{ Group 1 } & \multicolumn{2}{c|}{ Group 2 } & \multirow{2}{*}{$\begin{array}{c}\text { Normal } \\
\text { parameter }\end{array}$} \\
\cline { 2 - 6 } & Initial & $\begin{array}{c}\text { At the end of } \\
\text { observation }\end{array}$ & Initial & $\begin{array}{c}\text { At the end of } \\
\text { observation }\end{array}$ & $1,8 \pm 0,11$ \\
\hline Emotiogenic ED & $2,55 \pm 0,15$ & $2,34 \pm 0,18^{*}$ & $2,4 \pm 0,14$ & $2,1 \pm 0,21^{*}$ & $2,7 \pm 0,18$ \\
\hline External ED & $3,54 \pm 0,19$ & $3,12 \pm 0,21^{*}$ & $3,45 \pm 0,19$ & $2,55 \pm 0,14^{*}$ & $2,4 \pm 0,12$ \\
\hline Restrictive ED & $2,1 \pm 0,12$ & $2,0 \pm 0,11$ & $1,8 \pm 0,21$ & $2,95 \pm 0,23^{*}$ & \\
\hline
\end{tabular}

Note:* - significance of differences in the dynamics of observation $(\mathrm{p}<0.05)$

However, for group 2, the score for emotiogenic and external eating disorder was reduced, and the restrictive type of eating behavior, which presumably acts as a compensatory mechanism that suppresses the desire to eat in response to negative emotions (emotional behavior) and the appearance of food (external behavior), dominates that provides an additional contribution to the formation of motivation for observing the trainer's recommendations regarding nutrition.

All these changes testify to the effectiveness of an integrated method for correcting body weight through the inclusion of inhalation of highly concentrated oxygen with the addition of grapefruit oil.

\section{CONCLUSIONS}

The most common form of eating disorder was emotiogenic (60.6\%), with an average score of $3.87 \pm 0.65$. In group 2, in the dynamics of observation, the score for emotiogenic and external eating behavior decreased, and the restrictive type of eating disorder became dominant.

Inhalations of highly concentrated oxygen with the addition of grapefruit oil helped to reduce the index of hunger on the visual analogue scale by $72.2 \%(\mathrm{p}<0.05)$, increased the satiation by $14.1 \%(\mathrm{p}<0.05)$, parameters "Thoughts 
on food" and "Desired amount of food" decreased by $97.6 \%$ and $21.9 \%(p<0.05)$. Similar indexes in group 1 had slightly different trends - an increase in hunger (by 12.0\%), thoughts about food (by 7.9\%), and also the desired amount of food (by $9.9 \%$ ).

Stage-by-stage control analysis of data revealed a positive dynamics of the main indicators - a decrease in body weight, as well as a body mass index. In group 2, where inhalation of highly concentrated oxygen with the addition of grapefruit oil was used, a more significant change $(12.6 \%, \mathrm{p}<0.05)$ was achieved against group 1 , where the decrease in average body weight was only $4.3 \%$. In terms of body mass index in group 1, the decrease in BMI was $7.3 \%$, in group 2 $19.7 \%$.

A more significant decrease in BMI, WC, TC and the ratio of WC/TC was detected in the 2nd group of patients $(\mathrm{p}<0.05)$, who underwent by comprehensive program with inhalation of highly concentrated oxygen with grapefruit oil. In both groups, a decrease in WC, TC and WC/TC ratio was noted, but signs of abdominal distribution of adipose tissue still remained.

\section{REFFERENCE}

1. Ahmed, I. S., Hassan, M. A., \& Kondo, T. (2015). Effect of lyophilized grapefruit juice on P-glycoprotein-mediated drug transport in-vitro and in-vivo. Drug development and industrial pharmacy, 41(3), 375-381.

2. Akamine, Y., Miura, M., Komori, H., Tamai, I., Ieiri, I., Yasui-Furukori, N., \& Uno, T. (2015). The change of pharmacokinetics of fexofenadine enantiomers through the single and simultaneous grapefruit juice ingestion. Drug metabolism and pharmacokinetics, 30(5), 352-357.

3. Alam, M., Kauter, K., \& Brown, L. (2013). Naringin improves diet-induced cardiovascular dysfunction and obesity in high carbohydrate, high fat diet-fed rats. Nutrients, 5(3), 637-650.

4. Atkinson, T. J. (2008). Central and peripheral neuroendocrine peptides and signalling in appetite regulation: considerations for obesity pharmacotherapy. Obesity reviews, 9(2), 108-120.

5. Bastien, M., Poirier, P., Lemieux, I., \& Després, J. P. (2014). Overview of epidemiology and contribution of obesity to cardiovascular disease. Progress in cardiovascular diseases, 56(4), 369-381.

6. Beer-Borst, S., Morabia, A., Hercberg, S., Vitek, O., Bernstein, M. S., Galan, P., ... \& Panico, S. (2000). Obesity and other health determinants across Europe: the EURALIM project. Journal of Epidemiology \& Community Health, 54(6), 424-430.

7. Miyake, Y., Yamamoto, K., Morimitsu, Y., \& Osawa, T. (1998). Characteristics of antioxidative flavonoid glycosides in lemon fruit. Food Science and Technology International, Tokyo, 4(1), 48-53.

8. Castro-Vazquez, L., Alañón, M. E., Rodríguez-Robledo, V., Pérez-Coello, M. S., Hermosín-Gutierrez, I., DíazMaroto, M. C., ... \& Arroyo-Jimenez, M. D. M. (2016). Bioactive flavonoids, antioxidant behaviour, and cytoprotective effects of dried grapefruit peels (Citrus paradisi Macf.). Oxidative Medicine and Cellular Longevity, 2016.

9. Peterson, J. J., Beecher, G. R., Bhagwat, S. A., Dwyer, J. T., Gebhardt, S. E., Haytowitz, D. B., \& Holden, J. M. (2006). Flavanones in grapefruit, lemons, and limes: A compilation and review of the data from the analytical literature. Journal of food composition and analysis, 19, S74-S80.

10. Flegal, K. M., Kit, B. K., Orpana, H., \& Graubard, B. I. (2013). Association of all-cause mortality with overweight and obesity using standard body mass index categories: a systematic review and meta-analysis. Jama, 309(1), 71-82.

11. Ho, K. K., Anderson, K. M., Kannel, W. B., Grossman, W., \& Levy, D. (1993). Survival after the onset of congestive heart failure in Framingham Heart Study subjects. Circulation, 88(1), 107-115.

12. Hu, J., Shang, D., Xu, X., He, X., Ni, X., Zhang, M., ... \& Zhu, X. (2016). Effect of grapefruit juice and food on the pharmacokinetics of pirfenidone in healthy Chinese volunteers: a diet-drug interaction study. Xenobiotica, 46(6), 516-521.

13. Kartelishev, A.V.(2008). Principles of diet therapy and dietary prophylaxis in obese children and children of risk group. Pediatrics, 87(5): 73-77.

14. Okorodudu, D. O., Jumean, M. F., Montori, V. M., Romero-Corral, A., Somers, V. K., Erwin, P. J., \& LopezJimenez, F. (2010). Diagnostic performance of body mass index to identify obesity as defined by body adiposity: a systematic review and meta-analysis. International journal of obesity, 34(5), 791-799.

15. Van Gaal, L. F., Mertens, I. L., \& Christophe, E. (2006). Mechanisms linking obesity with cardiovascular disease. Nature, 444(7121), 875-880.

16. Voznesenskaya, T. G., \& Vachmistrov, A. V. (2001). Clinical and psychological analysis of eating disorders in obesity. J. Neurology and Psychiatry SS Korsakov, (12), 19-23.

17. Voznesenskaya, T. G. (2009). Eating behavior disorders in obesity and their correction. Farmateka, 12, 91-4.

18. Zvenigorodskaya, L. A., Mishchenkova, T. V., \& Tkachenko, E. V. (2009). Hormones and types of eating behavior, endocannabinoid system, food addiction in the developing metabolic syndrome. Consilum Medicum. Gastroenterology.(Suppl.), 1, 3-7. 